\title{
Analisis Pengaruh Kecelakaan Kerja Terhadap Pemenuhan Target Produksi Dengan Metode Regresi Linier di PD Tahu Al-Barokah
}

\author{
Isma Masrofah $^{1}$, Fery Hermawan ${ }^{2}$ \\ 1,2 Teknik Industri Universitas Suryakancana \\ Jl. Pasir Gede Raya, Kec. Cianjur, Kab. Cianjur, Jawa Barat 43216 \\ ${ }^{1}$ Isma.masrofah@unsur.ac.id , ${ }^{2}$ hermawanfery806@gmail.com
}

Dikirimkan: 12, 2019. Diterima: 12, 2019. Dipublikasikan: 12, 2019

\begin{abstract}
PD Tahu Al-Barokah is a company engaged in the production of tofu by utilizing soybeans as its main raw material. This company is one company that actively produces tofu every day to meet consumer demand, especially in the district of Cianjur. The problem in PD. Know Al-Barokah is the high level of work accidents in the production department. Where this study aimed to find out how much influence the level of work accidents on meeting production targets. The method used in this study is linear regression. The results of the correlation / relationship value $(R)$ of 0.779 obtained the output obtained a coefficient of determination ( $R$ Square) of 0.607 which means that the influence of the work accident variable on the variable fulfillment target of $60.7 \%$.
\end{abstract}

Keywords : linear regression, work accidents, production targets, fulfillment of production targets

\begin{abstract}
Abstrak - PD Tahu Al-Barokah merupakan perusahaan yang bergerak dibidang produksi tahu dengan memanfaatkan kedelai sebagai bahan baku utamanya. Perusahaan ini merupakan salah satu perusahaan yang aktif memproduksi tahu setiap harinya untuk memenuhi permintaan konsumen khususnya di kabupatun cianjur. Permasalah yang ada di PD Tahu Al-Barokah yaitu adanya kecelakaan kerja pada bagian produksi, yang diprediksi menjadi penyebab tidak tercapainya target pemenuhan produksi. Penelitian ini ditujukan untuk mengetahui seberapa besar pengaruh tingkat kecelakaan kerja terhadap pemenuhan target produksi. Metode yang digunakan pada penelitian ini yaitu regresi linier. Pengaruh variabel kecelakan kerja terhadap variabel pemenuhan target poduksi di PD Tahu Al-Barokah tidak signifikan, dengan persamaan regresi linier $\mathrm{Y}=$ 10432,638 - 66,057X. Hasil nilai korelasi / hubungan (R) yaitu sebesar 0,224 didapat output tersebut diperoleh koefisien determinasi (R Square) sebesar 0,05 yang terdapat pengertian bahwa pengaruh variabel kecelakan kerja terhadap variabel pemenuhan target poduksi sebesar $5 \%$.
\end{abstract}

Kata Kunci : regresi linier, kecelakaan kerja, target produksi, pemenuhan target produksi

\section{PENDAHULUAN}

Di dalam suatu perusahaan industri, faktor keselamatan kerja memegang peranan yang sangat penting. Oleh karna itu, banyak yang harus diperhatikan dan dijaga agar perusahaan mampu mengantisipasi terjadinya kecelakaan akibat kerja sedini mungkin, yaitu timbulnya kecelakaan yang berhubungan dengan aktivitas kerja, baik secara langsung maupun secara tidak langsung di perusahaan. Tujuan dari keselamatan kerja itu sendiri diantaranya adalah untuk melindungi tenaga kerja atas keselamatannya dalam melakukan pekerjaan-pekerjaan, untuk meningkatkan kesejahteraan hidup pekerja, meningkatkan produksi serta menjaga agar sumber-sumber produksi dapat terpelihara dengan baik sehingga dapat dipergunakan secara efisien dan aman untuk jangka waktu yang telah ditentukan.

Pentingnya keselamatan dan kesehatan kerja, didukung denga regulasi yang dikeluarkan pemerintah, seperti contohnya : Undang-undang Nomor 23 Tahun 1992 mengenai Kesehatan, Undang-undang Nomor 13 tahun 2003 tentang 
Ketenagakerjaan, Peraturan Menteri Tenaga Kerja Nomor 05 Tahun 1996 mengenai Sistem Manajemen Keselamatan dan Kesehatan Kerja, Peraturan Menteri Tenaga Kerja Nomor 04 Tahun 1967 mengenai Panitia Pembina Keselamatan dan Kesehatan Kerja serta Tata Cara Penunjukkan Ahli Keselamatan Kerja, Peraturan Menteri Tenaga Kerja No. 03/MEN/98 tentang Tata Cara Pelaporan dan Pemeriksaan Kecelakaan.

Setiap tahun di seluruh dunia, terjadi jutaan kecelakaan dari yang teringan sampai kepada yang terberat. Dari berbagai penyelidikan, ternyata faktor manusia dalam timbulnya kecelakaan sangat penting. Faktor kelalaian manusia mungkin menghasilkan sebanyak 85 hingga 95 persen dari semua kecelakaan [1]. PD Tahu Al-Barokah yang terletak di kampung pasir leutik kabupaten Cianjur merupakan salah satu perusahaan yang bergerak di bidang pengolahan bahan tahu yang merupakan bahan baku untuk kebutuhan makan yang dipasarkan di dalam pasar. Perusahaan ini melakukan proses produksi bahan baku tahu berdasarkan permintaan pasar, terutama dari produsen tahu, dan bahan-bahan lain yang terbuat dari kacang kedelai. Berdasarkan informasi yang diperoleh penulis, perusahaan ini merupakan salah satu perusahaan penghasil bahan baku tahu yang terbesar yang ada di kampung pasir leutik.

\section{Keselamatan Kerja dan Kesehatan Kerja}

K3 merupakan suatu program penting yang harus di adakan oleh suatu perusahaan. Adanya penerapan K3 bertujuan untuk menciptakan sistem yang meberikan kondisi selamat dan aman kepada semua yang terlibat dalam lingkungan kerja. Kondisi seperti ini akan memberikan sumber daya manusia yang optimal sehingga dapat memberikan kontribusi yang optimal dalam mewujudkan tujuan perusahaan.

Agar seorang tenaga kerja selalu berada dalam kondisi yang serasi yaitu dapat terjaminnya keadaan kesehatan dan produktivitas kerja yang tinggi, maka perlu adanya keseimbangan dari faktor-faktor berikut ini :

- Beban kerja

Setiap pekerjaan merupakan beban bagi pekerjanya/ pelakunya. Adapun beban kerja meliputi : beban fisik, beban mental, beban sosial.

- Beban tambahan akibat lingkungan kerja Sebagai tambahan kepada beban kerja terjadi dalam suatu lingkungan atau situasi yang berakibat adanya beban tambahan pada jasmani dan rohani. Adapun faktor penyebab beban tambahan adalah sebagai berikut : Faktor fisik (meliputi penerangan, suhu udara, kelembaban, cepat rambat udara, suaru, vibrasi mekanis, radiasi dan tekanan udara), faktor kimia (gas, uap, debu, kabut, asp, awan, cairan, dan sebagainya), faktor biologi (berasal dari golongan tumbuhan maupun hewan, misalnya kutu pada kursi), faktor fisiologis (kontruksi mesin, sikap dan cara kerja), faktor mental psikologis (suasana kerja, hubungan di antara pekerja atau dengan pengusaha, pemilihan kerja)

\section{Kecelakaan Kerja}

Kecelakaan merupakaan kejadian yang tidak terduga yang menyebabkan cedera atau kerusakan [2]. Kecelakaan dalam hal ini lebih cenderung timbul bukan karena adanya unsur kesengajaan apalagi direncanakan. Kecelakaan akibat kerja yang terjadi diperusahaan adalah kecelakaan yang berhubungan dengan aktivitas kerja baik secara langsung maupun tidak langsung di perusahaan [3].

Kecelakaan bekerja dapat digolongkan kedalam tiga kelompok yaitu : Kecelakaan akibat kerja di perusahaan, kecelakaan lalu lintas, kecelakaan di rumah.

Sedangkan kerugian yang disabakan oleh kecelakaan kerja dapat dikelompokan ke dalam 5 (lima) jenis, yaitu: kerusakan (mesin/peralatan), kekacauan organisasi, keluhan dan kesedihan, kelainan dan cacat, kematian.

\section{Kesehatan dan Keselamatan Kerja Industri Tahu}

Berdasarkan hasil survey Iwan, Florensa dan Meriastuti diketahui bahwa urutan proses yang dilakukan di industri tahu adalah perendaman, pencucian, penggilingan, perebusan, penyaringan, pencetakan/pengepresan, dan pemotongan [4].

Kecelakaan kerja yang terjadi pada industry ini terjadi karena faktor postur kerja dan safety. Masalah dari postur kerja dapat diatasi dengan perancangan meja kerja dengan prinsip ergonomi. Masalah safety dapat diatasi dengan perancangan meja kerja serta penampungan air[4].

\section{Analisis Regresi dan Korelasi}

Analisis regresi bertujuan untuk, mengestimasi atau menduga suatu hubungan antara variabel - variabel ekonomi, misalnya $\mathrm{Y}=$ $\mathrm{f}(\mathrm{x})$, melakukan peramalan atau prediksi nilai variabel terikat (tidak bebas) atau dependent variabel berdasarkan nilai

variabel terkait (variabel independen/bebas). Penetuan variabel mana yang bebas dan mana yang terkait dalam beberapa hal tidak mudah dilaksanakan. Studi yang cermat, diskusi yang seksama (dengan para pakar), berbagai pertimbangan, kewajaran masalah yang dihadapi dan pengalaman akan membantu memudahkan penetuan kedua variabel tersebut.

Langkah-langkah untuk menentukan persamaan hubungan antarvariabel sebagai berikut 
- Mengumpulkan data dari variabel yang dibutuhkan misalnya $\mathrm{X}$ sebagai variabel bebas dan Y sebagai variabel tidak bebas.

- Menggambarkan titik-titik pasangan (x,y) dalam sebuah sistem koordinat bidang. Hasil dari gambar itu disebut Scatter Diagram (Diagram Pencar/Tebaran) dimana dapat dibayangkan bentuk kurva halus yang sesuai dengan data. Kegunaan dari diagram pencar adalah membantu menunjukkan apakah terdapat hubungan yang bermanfaat antara dua variabel dan membantu menetapkan tipe persamaan yang menunjukkan hubungan antara kedua variabel tersebut.

- Menentukan persamaan garis regresi dengan mencari nilai-nilai koefisien regresi dan koefisien korelasi.

Korelasi merupakan teknik analisis yang melihat kecenderungan pola dalam satu variabel berdasarkan kecenderungan pola dalam variabel yang lain. Jika kecenderungan dalam satu variabel selalu diikuti oleh kecenderungan dalam variabel lain, kita dapat mengatakan bahwa kedua variabel ini memiliki hubungan atau korelasi.

Studi yang membahas tentang derajat hubungan antara variabel-variabel dikenal dengan nama korelasi. Ukuran yang dipakai untuk mengetahui derajat hubungan, terutama untuk data kuantitatif dinamakan koefisien korelasi

\section{Metodologi Penelitian}

Guna mendapatkan hasil penelitian yang baik maka diperlukan urutan langkah-langkah penelitian yang tepat, adapun langkah-langkah penelitian yang di lakukan dapat dilihat pada Gambar 1. Flow chart penelitian.

\section{Identifikasi Masalah}

Pada tahap identifikasi masalah dapat ditentukan masalah apa yang sering dialami oleh perusahaan, kemudian dari hasil identifikasi maalah tersebut dapat ditentukan tujuan penelitian yang akan dicapai

\section{Hipotesis Penelitian}

Hipotesis merupakan dugaan awal atau jawaban sementara terhadap fenomena penelitian dan akan diuji berdasarkan hasil penelitian lapangan hipotesis penelitian ini dirunuskan sebagai berikut yaitu "Variabel kecelakaan kerja memiliki pengaruh yang nyata terhadap pemenuhan target produksi”.

\section{Studi Pustaka}

Studi pustaka bertujuan untuk mendapatkan konsep serta metode yang berhubungan dengan masalah yang terjadi, sehingga dapat mengindentifikasi data yang diperlukan untuk melakukan penelitian ini. Teori-teori yang dipelajari pada penelitian ini adalah teori mengenai keselamatan kerja dan pencegahan kecelakaan

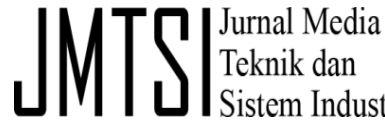

kerja, serta beberapa teori-teori statistik yang digunakan sebagai metode dasar pada pengolahan data.

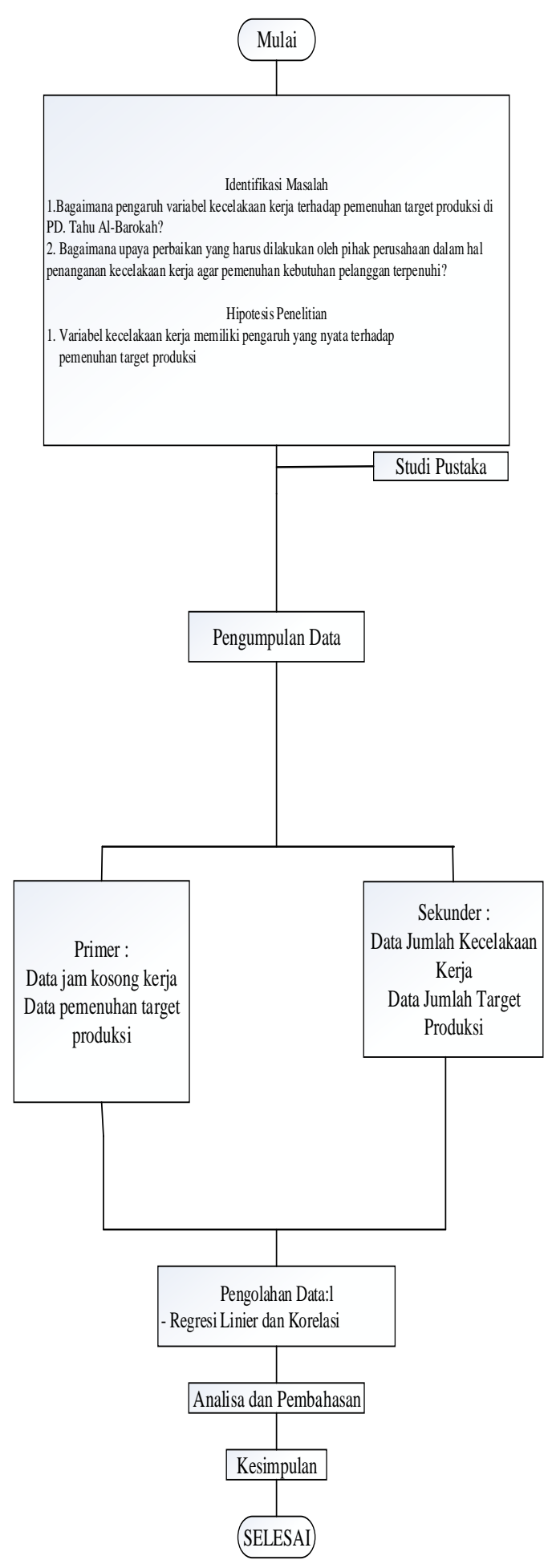

Gambar 1. Flow chart penelitian

\section{Pengumpulan Data}

Pengumpulan data primer (data jam kosong kerja dan Data pemenuhan target produksi) dilakukan 
dengan metode wawancara dan pengamatan langsung dilapangan, sedangkan untuk mendapatkan data sekunder (data jumlah kecelakaan kerja dan data jumlah produksi) dilakukan dengan pengumpulan data dari dokumen yang dimiliki oleh perusahaan.

\section{Pengolahan Data}

Data yang telah terkumpul diolah dengan menggunakan model regresi linier dengan tujuan untuk mengetahui hubungan dari variabel independen (kecelakaan kerja) terhadap variabel dependen (pemenuhan target produksi).

\section{Analisis Data dan Pembahasan}

Setelah perancangan model selesai maka dilakukan analisis data untuk memcari jalan keluar dari permasalahan yang diteliti.

Kesimpulan Dan SaranKesimpulan dan saran adalah menyimpulkan hasil dari penelitian ini utuk memperbaiki masalah yang terjadi diperusahaan dan memberikan saran yang sudah diteliti guna memberi keuntungan bagi perusahaan.

\section{Hasil PENELITIAN}

\section{Data Penelitian}

Hasil pengamatan pada Proses Produksi pembuatan tahu di PD Tahu Al-Barokah dapat dilihat pada tabel I, II dan III.

TABEL I

DATA JUMLAH KECELAKAAN KERJA

PD TAHU AL-BAROKAH PERIODE TAHUN 2016 - 2017

\begin{tabular}{|c|c|c|c|c|c|c|c|}
\hline \multirow{2}{*}{ Tahun } & \multirow{2}{*}{ Periode } & \multicolumn{5}{|c|}{ Jenis Kecelakaan Kerja } & \multirow{2}{*}{ Keterangan } \\
\hline & & 1 & 2 & 3 & 4 & Jumlah & \\
\hline \multirow{12}{*}{2016} & Januari & 1 & 1 & & & 2 & Orang \\
\hline & Februari & 2 & & 1 & & 3 & Orang \\
\hline & Maret & & 3 & & & 3 & Orang \\
\hline & April & 4 & 1 & & & 5 & Orang \\
\hline & Mei & & 1 & 2 & 1 & 4 & Orang \\
\hline & Juni & & & & & 0 & Orang \\
\hline & Juli & 2 & 1 & & & 3 & Orang \\
\hline & Agustus & & & 3 & 2 & 5 & Orang \\
\hline & \multicolumn{2}{|l|}{ September } & & & & 0 & Orang \\
\hline & Oktober & 1 & & 2 & 1 & 4 & Orang \\
\hline & November & & & 1 & 1 & 2 & Orang \\
\hline & Desember & & 2 & & 4 & 6 & Orang \\
\hline \multirow{12}{*}{2017} & Januari & - & - & 2 & 3 & 5 & Orang \\
\hline & Februari & 1 & - & 1 & - & 2 & Orang \\
\hline & Maret & - & 2 & - & - & 2 & Orang \\
\hline & April & 2 & 1 & - & - & 3 & Orang \\
\hline & Mei & - & 1 & 1 & 1 & 3 & Orang \\
\hline & \begin{tabular}{|l|} 
Juni \\
\end{tabular} & - & - & - & - & 0 & Orang \\
\hline & Juli & 3 & 2 & - & - & 5 & Orang \\
\hline & Agustus & - & - & 2 & 2 & 4 & Orang \\
\hline & Septemben & - & - & - & - & 0 & Orang \\
\hline & Oktober & 1 & - & 1 & 1 & 3 & Orang \\
\hline & November & - & - & 1 & 4 & 5 & Orang \\
\hline & Desember & - & 3 & - & 2 & 5 & Orang \\
\hline
\end{tabular}

TABEL II

DATA TARGET DAN JUMLAH PRODUKSI

PD. TAHU AL-BAROKAH PERIODE TAHUN 2016 - 2017

\begin{tabular}{|c|l|c|c|}
\hline Tahun & Bulan & Data Target Produksi (Kg) & Data Jumlah Produksi (K) \\
\hline \multirow{8}{*}{2016} & Januari & 9300 & 9026 \\
\cline { 2 - 4 } & Februari & 8700 & 8125 \\
\cline { 2 - 4 } & Maret & 9300 & 8970 \\
\cline { 2 - 4 } & April & 9000 & 8546 \\
\cline { 2 - 4 } & Mei & 9300 & 8725 \\
\cline { 2 - 4 } & Juni & 9000 & 8856 \\
\cline { 2 - 4 } & Juli & 9300 & 8825 \\
\cline { 2 - 4 } & Agustus & 8700 & 8125 \\
\cline { 2 - 4 } & September & 9000 & 8905 \\
\cline { 2 - 4 } & Oktober & 9300 & 9028 \\
\cline { 2 - 4 } & November & 9000 & 8700 \\
\cline { 2 - 4 } & Desember & 9300 & 9028 \\
\hline \multirow{5}{*}{2017} & Januari & 12400 & 11300 \\
\cline { 2 - 4 } & Februari & 11200 & 10780 \\
\cline { 2 - 4 } & Maret & 12400 & 11200 \\
\cline { 2 - 4 } & April & 12400 & 11100 \\
\cline { 2 - 4 } & Mei & 12400 & 11300 \\
\cline { 2 - 4 } & Juni & 12000 & 11700 \\
\cline { 2 - 4 } & Juli & 12400 & 11200 \\
\cline { 2 - 4 } & Agustus & 12400 & 11900 \\
\cline { 2 - 4 } & September & 12000 & 11600 \\
\hline & Oktober & 12400 & 11500 \\
\hline & November & 12000 & 11200 \\
\cline { 2 - 4 } & Desember & 12400 & 11100 \\
\hline
\end{tabular}

TABEL III

DATA JAM KOSONG KERJA

PD TAHU AL-BAROKAH PERIODE TAHUN 2016 - 2017

\begin{tabular}{|c|c|c|c|c|c|c|}
\hline \multirow{2}{*}{ Tahun } & \multirow{2}{*}{ Periode } & \multicolumn{4}{|c|}{ Jam Kosong Kerja } & \multirow{2}{*}{ Keterangar } \\
\hline & & 1 & 2 & 3 & 4 & \\
\hline \multirow{12}{*}{2016} & Januari & 7 & 0 & 0 & 0 & Hari \\
\hline & Februari & 7 & 0 & 6 & 0 & Hari \\
\hline & Maret & 0 & 2 & 0 & 0 & Hari \\
\hline & April & 17 & 0 & 0 & 0 & Hari \\
\hline & Mei & 0 & 0 & 6 & 2 & Hari \\
\hline & Juni & 0 & 0 & 0 & 0 & Hari \\
\hline & Juli & 4 & 1 & 0 & 0 & Hari \\
\hline & Agustus & 0 & 0 & 6 & 3 & Hari \\
\hline & September & 0 & 0 & 0 & 0 & Hari \\
\hline & Oktober & 5 & 0 & 3 & 2 & Hari \\
\hline & November & 0 & 0 & 1 & 1 & Hari \\
\hline & Desember & 0 & 2 & 0 & 5 & Hari \\
\hline \multirow{12}{*}{2017} & Januari & 0 & 0 & 3 & 2 & Hari \\
\hline & Februari & 7 & 0 & 4 & 0 & Hari \\
\hline & Maret & 0 & 2 & 0 & 0 & Hari \\
\hline & April & 3 & 0 & 0 & 0 & Hari \\
\hline & Mei & 0 & 0 & 3 & 2 & Hari \\
\hline & Juni & 0 & 0 & 0 & 0 & Hari \\
\hline & Juli & 8 & 2 & 0 & 0 & Hari \\
\hline & Agustus & 0 & 0 & 3 & 3 & Hari \\
\hline & September & 0 & 0 & 0 & 0 & Hari \\
\hline & \begin{tabular}{|l|} 
Oktober \\
\end{tabular} & 7 & 0 & 3 & 2 & Hari \\
\hline & November & 0 & 0 & 4 & 3 & Hari \\
\hline & Desember & 0 & 1 & 0 & 4 & Hari \\
\hline
\end{tabular}




\section{Pengolahan Data}

Data yang diperoleh diolah menggunakan model regresi linier dan koefisien kolerasi, dengan menggunakan software spss. Adapun hasil pengolahan data dapat dilihat pada tabel IV, V, dan VI.

TABEL IV

UJI REGRESI

ANOVA $^{b}$

\begin{tabular}{|l|r|r|r|r|r|}
\hline Model & $\begin{array}{l}\text { Sum of } \\
\text { Squares }\end{array}$ & Df & Mean Square & F & Sig. \\
\hline Regression & $2.111 \mathrm{E} 6$ & 1 & 2111220.573 & 1.157 & .294 \\
Residual & $4.015 \mathrm{E} 7$ & 22 & 1825133.881 & & \\
Total & $4.226 \mathrm{E} 7$ & 23 & & & \\
\hline
\end{tabular}

a. Predictors: (Constant), Kecelakaan Kerja

b. Dependent Variable: Data Jumlah Produksi

TABEL V UJI KORELASI

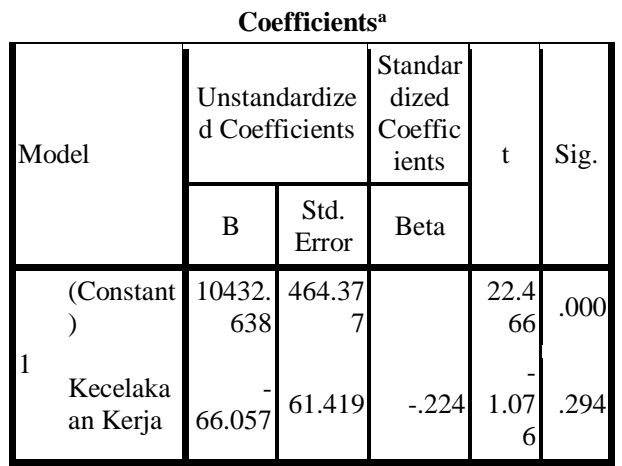

a. Dependent Variable: Data Jumlah Produksi

\section{Uji Korelasi}

- Hipotesis :

Ho : $\beta=0$

Hi : $\beta \neq 0$, dimana $i=0.1 .2$ dan 3

- $\quad$ Tingkat signifikan : $\alpha=5 \%$

Besarnya kontribusi variabel independen terhadap variabel dependen, maka akan dilakukan analisis koefisien determinasi.

TABEL VI

NILAI DETERMINASI

Model Summary

\begin{tabular}{|c|r|r|r|r|}
\hline Model & \multicolumn{1}{|c|}{$\mathrm{R}$} & R Square & $\begin{array}{l}\text { Adjusted } \\
\text { R Square }\end{array}$ & $\begin{array}{r}\text { Std. Error of } \\
\text { the Estimate }\end{array}$ \\
\hline 1 & $.224^{\mathrm{a}}$ & .050 & .007 & 1350.97516 \\
\hline
\end{tabular}

a. Predictors: (Constant), Kecelakaan Kerja

\section{PEMBAHASAN}

\section{Pengaruh Variabel Kecelakaan Kerja dan}

\section{Terhadap Pemenuhan Target Produksi}

Dari output diketahui bahwa nilai $\mathrm{F}$ hitung = 1,157 dengan tingkat signifikan sebesar 0,294 > 0,05 , maka model regresi ini tidak cukup untuk dapat dipakai memprediksi variabel pemenuhan target produksi karena pengaruh variabel kecelakaan kerja $(\mathrm{X})$ terhadap variabel pemenuhan taget produksi $(\mathrm{Y})$ terbukti tidak signifikan.

Persamaan Regresi yang diberikan adalah sebagai berikut :

$$
\begin{aligned}
& Y=a+b X \\
& Y=10432,638-66,057 X
\end{aligned}
$$

Nilai konstanta dari persamaan regresi (a) sebesar 10432,638, sedangkan nilai koefisien regresi untuk variabel kecelakaan kerja (b) sebesar $-66,057$. Persamaan ini dapat menjelaskan :

- Konstanta 10432,638, mengandung arti bahwa nilai konsisten variabel pemenuhan target produksi adalah sebesar 10432,638.

- Koefisien regresi X sebesar -66,057 menyatakan bahwa setiap penambahan $1 \%$ nilai kecelakan kerja, maka nilai pemenuhan menurun sebesar 66,057. Koefisien regresi ini bernilai negatif, sehingga dapat dikatakan bahwa arah pengaruh variabel $\mathrm{X}$ dan $\mathrm{Y}$ adalah negatif.

\section{Besarnya Pengaruh Variabel Kecelakaan kerja dan Pemenuhan Target produksi}

Tabel VI menunjukkan Nilai Korelasi (R) adalah 0.224 dan nilai koefisien determinasi $(\mathrm{R}$ Square) adalah 0.05 , yang mengandung pengertian bahwa pengaruh variabel kecelakaan kerja terhadap variabel pemenuhan target produk adalah kecelakaan kerja terhadap variabel pemenuhan target produk adalah sebesar $5.0 \%$

Berdasarkan hasil regresi dan nilai korelasi dapat diketahui bahwa jumlah pemenuhan target produksi di PD Tahu Al-Barokah tidak ditentukan oleh banyaknya kecelakaan kerja.

\section{KESIMPULAN}

Kesimpulan yang dapat diambil dari hasil pembahasan yaitu :

- Pengaruh kecelakaan kerja terhadap pemenuhan target produksi di PD Tahu AlBarokah tidak signifikan.

- Persaman Regresi Linier pengaruh kecelakaan kerja terhadap pemenuhan target produksi di 
- $\quad$ PD Tahu Al-Barokah adalah Y = 10432,638 - 66,057X

- Berdasarkan nilai korelasi, pengaruh variabel kecelakaan kerja terhadap variabel pemenuhan target produk adalah sebesar $5.0 \%$

\section{REFERENSI}

[1] M. A. Friend and J. P. Kohn, Fundamentals of Occupational Safety and Health-Government Institutes, 4th ed. United States of America.: Government Institutes, an imprint of The Scarecrow Press, Inc., 2007.

[2] J. Ridley, Health and Safety in Brief. Elsevier Ltd., 2008.

[3] Suma'mur, Hiegiene Perusahaan dan Keselamatan Kerja (Hiperkes). Jakarta: Sagung Seto, 2009.

[4] I. A. Soenandi, F. R. Purba, and M. Ginting, "PKM Peningkatan Kesehatan dan Keselamatan Kerja Industri Tahu Semanan," in Prosiding Seminar Nasional Hasil Pengabdian Kepada Masyarakat, 2019, pp. 355-359. 